\title{
Environment outweighs the effects of fishing in regulating demersal community structure in an exploited marine ecosystem
}

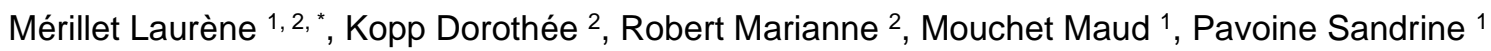

1 UMR 7204 MNHN-UPMC-CNRS Centre d'Ecologie et de Sciences de la COnservation 43 rue BuffonCP135, 75005 Paris , France

2 Ifremer, Unité de Sciences et Technologies halieutiques Laboratoire de Technologie et Biologie Halieutique 8 rue François Toullec 56100 Lorient, France

* Corresponding author : Laurène Mérillet, email address : Laurene.Merillet@ifremer.fr

\begin{abstract}
:
Global climate change has already caused bottom temperatures of coastal marine ecosystems to increase worldwide. These ecosystems face many pressures, of which fishing is one of the most important. While consequences of global warming on commercial species are studied extensively, the importance of the increase in bottom temperature and of variation in fishing effort is more rarely considered together in these exploited ecosystems. Using a 17-year time series from an international bottom-trawl survey, we investigated co-variations of an entire demersal ecosystem (101 taxa) with the environment in the Celtic Sea. Our results showed that over the past two decades, biotic communities in the Celtic Sea were likely controlled more by environmental variables than fisheries, probably due to its long history of exploitation. At the scale of the entire zone, relations between taxa and the environment remained stable over the years, but at a local scale, in the center of the Celtic Sea, dynamics were driven by inter-annual variation in temperature. Fishing was an important factor structuring species assemblages at the beginning of the time series (2000) but decreased in importance after 2009. This was most likely caused by a change in spatial distribution of fishing effort, following a change in targeted taxa from nephrops to deeper water anglerfish that did not co-vary with fishing effort. Increasing bottom temperatures could induce additional changes in the coming years, notably in the cold-water commercial species cod, hake, nephrops and American plaice. We showed that analyzing co-variation is an effective way to screen a large number of taxa and highlight those that may be most susceptible to future simultaneous increases in temperature and changes in exploitation pattern by fisheries. This information can be particularly relevant for ecosystem assessments.
\end{abstract}

Keywords : bottom trawl survey, Celtic Sea, fishing effort, marine resources, Spatio-temporal dynamics, stability, STATICO multivariate analysis 


\section{INTRODUCTION}

Effects of climate change are increasingly visible in marine ecosystems worldwide (IPCC, 2014), and one of the largest concerns is maintaining fish populations and their habitats in states sufficiently stable to enable them to sustain a growing human population, as emphasized by the $14^{\text {th }}$ Sustainable Development Goal of UNESCO (Griggs, Nilsson, Stevance, \& McCollum, 2017). Although coastal shelf seas represent only $c a .7 \%$ of the ocean surface area, they provide $30 \%$ of oceanic primary production and $90 \%$ of global fish catches (Jönsson, Salisbury, \& Mahadevan, 2011; Pauly et al., 2002). These easily accessible areas have been exploited for centuries, and most have already experienced shifts in their biotic communities due to selective removal of target species (Guénette \& Gascuel, 2012), leading to alternate stable states (Beisner, Haydon, \& Cuddington, 2003) in which the importance of fishing pressure has progressively decreased. Indeed, progressive enforcement of fishing regulations in the past 40 years has lowered

This article is protected by copyright. All rights reserved 
exploitation rates by decreasing fishing pressure in developed countries, notably in the North-East Atlantic (Fernandes \& Cook, 2013). The biomass of several important stocks increased from 2002-2011, indicating signs of recovery (Fernandes \& Cook, 2013); however, these metrics are based only on commercial species. This focus on commercial species has been widely contested by the need for a more systemic assessment of the health of ecosystems, as stressed by the Ecosystem-based Approach to Fisheries (Garcia, Zerbi, Aliaume, Do Chi, \& Lasserre, 2003), that implies including non-commercial species as well.

Today, the stability of these ecosystems continues to be challenged by climate change, whose impact is particularly visible in coastal ecosystems (Belkin, 2009) through the increase in temperature, increase in ocean acidification or change in pattern of primary production or fish distribution (Dulvy et al., 2008; Fabry, Seibel, Feely, \& Orr, 2008; Fossheim et al., 2015; Henson et al., 2010). The first changes in marine communities attributable to climate change - increased bottom temperatures and modified fish distributions - were observed in the past 20 years (Dulvy et al., 2008). These changes can superimpose their effects on the many pressures already facing coastal ecosystems, from human activities (e.g. fishing, aquaculture, dredging, offshore structures, leisure, runoff from land) to natural perturbations such as the North Atlantic Oscillation (NAO) and the Atlantic Multidecadal Oscillation (AMO) (Edwards, Beaugrand, Alheit, Helaouët, \& Coombs, 2013; ICES, 2018a; Wakelin, Artioli, Butenschön, Allen, \& Holt, 2015).

Managing exploited ecosystems in the context of the global climate change thus required accounting for synergistic effect of climate and fishing (Le Bris et al., 2018; Planque et al., 2010). Integrating multiple environmental drivers and ecosystem components simultaneously for a large number of species is necessary, especially to predict which species would be impacted the most by changes in several environmental variables acting in interaction. Among those other variables, primary productivity is particularly important to consider as it enables to account for the response of species to the input of energy in the system. In the context of an increasing number of reliable data sources that provide time series of environmental variables (such as the European Union's Copernicus marine environment monitoring service, Sotillo et al. 2015) and international marine surveys that sample increasingly larger areas of ecosystems, this goal becomes achievable.

Located on the continental shelf between France, Ireland and the United Kingdom (UK), the Celtic Sea lies at the biogeographical border between two faunal assemblages: warm-water species from the southern Bay of Biscay and Portuguese coasts and cold-water boreal species from western Ireland and the North Sea (Hátún et al., 2009). This geographical position leads to a 
higher number of species in the Celtic Sea ( $>350$ sampled during International Bottom Trawl Surveys) than in the surrounding seas but also implies that these species may be impacted more by environmental variations, since some are at the limits of their area of distribution (ICES, 2018a; Thomson et al., 2015). Regional warming has been detected in the whole Celtic Sea, with the winter bottom temperature increasing significantly over the time series as studied by ter Hofstede, Hiddink, \& Rijnsdorp (2010), i.e. from 1993 to 2008. This was most likely caused by the warm phase of the AMO in the late 1990s (McLean, Mouillot, Goascoz, Schlaich, \& Auber, 2018). This increase in temperature coincided with expansion of warm-water fish from southern Portugal to northwestern Ireland (Quero, Du Buit, \& Vayne, 1998). However, having a closer look at the time series, the temperature appears to have stabilized after 2002 (regression of bottom temperature on 2000-2016 showed non-significant trend: slope $=-0.002$, $p$-value $=0.83$ ). Local dynamics also have to be investigated as they might show different trends than the ones observed over the whole area. Primary production, approximated by chlorophyll a concentration, was relatively high (0.36-1.63 $\mathrm{mg} \cdot \mathrm{m}^{-3}$ ) in the Celtic Sea (ICES, 2018a) but might decrease, according to simulations run under the A2 greenhouse-gas-emission scenario of the Intergovernmental Panel on Climate Change (Henson et al., 2010). The Celtic Sea is also an important fishing zone, intensively exploited by France, Ireland, the UK, Belgium and Spain since at least the 1950s (Guénette \& Gascuel, 2012). It sustains an important fishery of more than 100 species, from algae to top-predator fishes (Mateo, Pawlowski, \& Robert, 2017). After major changes occurred in the 1950-1970, a decreasing trend of fishing mortality has been reported since the mid-1990 for assessed benthic and demersal stocks (ICES, 2018b). Previous studies in the Celtic Sea described communities in relation to fishing and oceanographic variables, at relatively local geographical and temporal scales, around the banks in the center of the Sea (Martinez, Ellis, Scott, \& Tidd, 2013; Mateo et al., 2017; Sharples, Ellis, Nolan, \& Scott, 2013). However, the question of their long-term and large-scale variability remains to be addressed.

The Celtic Sea thus offers a good case study to investigate the synergistic importance of bottom temperature, fishing and primary productivity in driving communities of this NorthAtlantic exploited shelf sea over the past 20 years. In particular, we aimed to assess whether taxa responded to spatial variations in bottom and pelagic trawl effort and in bottom temperature, or to spatio-temporal variations in chlorophyll a concentration from 2000-2016. Knowing the relatively weak range of variations of the average bottom temperature (warm phase of the AMO) and fishing (stable or decreasing exploitation patterns) over the studied period at the regional scale of the 
Celtic Sea, we expected only minor temporal variations in these variables to manifest themselves at the assemblage level. However, we expected that spatial variations in these temperature and fishing variables and temporal variations at a local scale may still be important in driving the composition of specific species assemblages. We used a dataset of 1175 hauls from the International Bottom Trawl Survey EVHOE (Evaluation des ressources Halieutiques de 1'Ouest de l'Europe). We considered 101 commercial and non-commercial taxa (i.e. fish, cephalopods, bivalves and crustaceans) to account for variation in the entire bentho-demersal ecosystem with the environment. We characterized the species assemblages from 2000-2016 as a function of depth, sediments, chlorophyll a, bottom temperature and fishing, where fishing and warming effects had already occurred. Since this relation may vary according to the spatial scale (deYoung et al., 2008), we studied two spatial scales: large scale (the entire Celtic Sea) and a finer scale (four sediment-depth strata). We characterized (1) temporal stability of relations between taxa and the environment and the possible presence of shifts in the relations, (2) average structuring of the community over this period and assemblages of taxa showing similar co-variation with climatic, anthropogenic and biological variables and (3) variation in this structure over the years and among sediment-depth strata.

\section{METHODS}

\section{Sampling and taxa}

We extracted data from the bottom trawl survey EVHOE, part of the International Bottom Trawl Survey (ICES 2015), that was conducted each year in the Celtic Sea in November from 2000-2016. The trawl was a 36/47 GOV (grande ouverture verticale) with a $20 \mathrm{~mm}$ net fitted in the codend, a horizontal opening of $c a .20 \mathrm{~m}$ and vertical opening of $4 \mathrm{~m}$. A total of 53-84 hauls were performed each year according to a random stratified design based on depth strata. Hauls were conducted at 4 knots for $30 \mathrm{~min}$. Our study used 1175 valid hauls. Due to less precise identification of certain taxa early in the time series, some species were grouped at a lower taxonomic level (hereafter, “taxon”) (genus, for species of Alloteuthis, Argentina, Arnoglossus, Gaidrosparus, Loligo, Munida, Mustelus, Octopus, Pomatoschistus and Sepiola; family, for Ammodytidae and Gobiidae). Only the taxa that occurred at more than 5\% of the sampling sites in at least one EVHOE depth strata over the time series were kept for analysis and considered as correctly sampled. A total of 101 taxa from 6 classes (Actinopterygii, Bivalvia, Cephalopoda, Elasmobranchii, Holocephali and Malacostraca) and 53 families were selected. We worked at the 
scale of the sampling stations and the biomasses were standardized per $\mathrm{m}^{2}$ by dividing by the sampled area. The sampled area at each sampling site was computed from the geographic position at the beginning and the end of the haul that gave us the distance sampled, that we multiplied by the width of the net at each haul. Sampling sites were located at depths of 57-340 m (Fig. 1), mainly on sand and mud, with some mixed, coarse sediments and boulders.

\section{Environmental and fishing variables}

Based on the literature (Foveau, Vaz, Desroy, \& Kostylev, 2017; Karakassis \& Eleftheriou, 1997; Vaz, Carpentier, \& Coppin, 2007), we selected variables known to influence Northern Atlantic sea shelf ecosystems and that characterize habitat (depth, sediments). We also selected variables to capture the driving of demersal communities by environment (bottom temperature and chlorophyll a concentration as a proxy for productivity) and human activities (fishing effort). These variables do not influence all taxa at the same time, neither with the same time lag. Due to the annual frequency of sampling and the differing life cycles of the 101 taxa, we assumed that annual means would be the most relevant values for the variables.

Depth was recorded at each sampling site, and sediment type (according to the Folk five-class classification) was extracted using a spatial join to EMODnet data (https://www.emodnetgeology.eu). Because the sediment map provided by EMODnet did not cover the entire study area (93 of 1175 sampling sites missing), we obtained the missing values from France's Service Hydrographique et Océanographique de la Marine (SHOM) world sediment map (https://diffusion.shom.fr/loisirs/sedim-mondiale.html). Bottom temperature and chlorophyll a concentration were downloaded from Copernicus (http://marine.copernicus.eu/). Annual mean chlorophyll a concentrations were calculated from monthly means obtained from satellite observations at $1 \mathrm{~km} \times 1 \mathrm{~km}$ resolution.

Annual mean bottom temperatures were calculated from the monthly mean Atlantic-Iberian Biscay Irish-Ocean Physics Reanalysis data product at $8 \mathrm{~km} \times 8 \mathrm{~km}$ resolution. Information about fishing effort came from the New Fisheries Dependent Information from the EU's Scientific, Technical and Economic Committee for Fisheries (STECF) (https://stecf.jrc.ec.europa.eu/), which provided fishing effort for all European countries in hours fished and landings in tonnage, both per statistical rectangle $(111.12 \mathrm{~km} \times 55.56 \mathrm{~km})$. Analysis was realized on fishing hours data while landings data were used to give insights during the interpretation step only (Appendix 3, Fig. S5, S7 and S9). We considered pelagic and bottom trawls since they represent the largest and second- 
largest landings, respectively. We hereafter refer to these variables as "environmental variables". To interpret outputs of the statistical analysis, we generated maps of yearly anomalies (pixel value of a given year - pixel mean value over the time series) for chlorophyll a, bottom temperature and bottom trawl effort (spatial coverage was insufficient for pelagic trawl effort) (Fig. 7a, 7b, 8a, and Appendix 2, Fig. S1 to S4) as well as a map of the slope of the regression of bottom temperature over time (Fig. 8b). We also assessed temporal evolution in fishing effort and landings of bottom and pelagic trawls (Appendix 3, Fig. S5 to S9).

\section{Statistical analysis: STATICO}

Ordination analyses are widely used to study relations between taxa and their environment (Thioulouse et al., 2004). Given the expected complexity of the relations between climatic, anthropogenic and biological variables, we chose STATICO analysis (Simier et al., 1999; Thioulouse et al., 2004) to identify potential relations between taxa biomass and environmental variables, without imposing causal relations. This method is particularly suited for analyzing both temporally stable and temporally variable relations between taxa and their environment (Thioulouse et al., 2004).

STATICO is based on two tables: a sites $\times$ taxa table, which provides biomass for each taxon at each site sampled, and a sites $\times$ environments table, which provides values for each environmental variable at each site. We defined the two tables for each year from 2000-2016. Although the sites sampled varied from year to year, the tables contained the same lists of taxa and environmental variables. As recommended by Rao (1995), we applied Hellinger's transformation to the biomass data to avoid placing undue emphasis on taxa with low frequencies when measuring similarities between samples. Bottom and pelagic trawl efforts were log-transformed because they had wide ranges. To avoid unbalanced sampling among sediment types, we recorded them as a numeric variable (1-5), with larger values representing larger particle size (1=Mud to muddy with muddy characterized by $100-10 \%$ mud, $<90 \%$ sand and $<5 \%$ gravel; $2=$ Sand; $3=$ Mixed sediment characterized by $95-10 \%$ mud, $<90 \%$ sand and $>=5 \%$ gravel; $4=$ Coarse substrate being either $>=80 \%$ gravel or $>=5 \%$ gravel and $>=90 \%$ sand; $5=$ Rock $\&$ Boulders).

The first step of STATICO consists of co-inertia analysis that combines, for each year, the sites $\times$ taxa table with the sites $\times$ environments table, yielding a cross-covariance table. For each year, the cross-covariance table shows the environmental variables as rows, the taxa as columns and, as entries, the covariance between each taxon and environmental variable for all sample sites. 
Each co-inertia analysis (for each year) was based on a normed principal component analysis $(\mathrm{PCA})$ of the sites $\times$ taxa table and a normed PCA of the sites $\times$ environments table. Since this step assumes a linear relation between taxa biomass and environmental variables, we visually verified that the relation between each pair of taxon and environmental variable was roughly linear. The second step of STATICO consists of partial triadic analysis (PTA, Tucker 1966, Thioulouse et al. 2018) to analyze the series of cross-covariance tables over the years. The PTA has three steps:

(1) Interstructure. For each pair of years (i.e. each year with every other year), vectorial correlation coefficients $R v$ are calculated between their (environments $\times$ taxa) cross-covariance tables to identify similarities between these two tables. All pairwise $R v$ values are placed in a squared Rv matrix, which is diagonalized into eigenvectors and eigenvalues to define scores for the years that describe, in multidimensional space, similarities between their (environments $\times$ taxa) cross-covariance tables. The interstructure thus evaluates how similar the relationships between the biomass of taxa and the environmental variables have been over years. On the correlation circle, the length of the arrows associated with years on the first axis represented the weights used to calculate the weighted mean of the (environments $\times$ taxa) cross-covariance tables in the compromise analysis. The longer the arrow, the greater the contribution of a year to the compromise.

(2) Compromise. The first eigenvector of the interstructure analysis is used to weight the crosscovariance tables and calculate their weighted mean. A high weight for a given year indicates that this year is particularly representative of the relation between taxa and the environment during the time series. Conversely, a low weight means that the given year has unusual relations between taxa and the environment. Similar weights for all years indicate stable relations between taxa and the environment over the years. The structure of the averaged cross-covariance table is then calculated using a centered PCA, which yields factorial maps with comparable scores for the taxa and environmental variables. The compromise thus assesses temporally stable relations between taxa biomass and environmental variables.

(3) Intrastructure. The rows (environmental variables) and columns (taxa) of each crosscovariance table for each year are projected onto the compromise space as supplementary elements (Thioulouse et al. 2018). To assess potential spatial patterns in taxa-environment relations, we projected the rows (sampling sites) of the initial sites $\times$ taxa and sites $\times$ environments tables onto the compromise space as supplementary elements. These projections provide an overview of annual variations in taxa-environment relations. The intrastructure 
thus assesses temporal changes in relations between taxa biomass and environmental variables, also called trajectories.

To obtain an integrated view of variations in taxa biomass and the environment, we clustered taxa according to their mean relation with the environment. We used k-means clustering on the taxa scores in the compromise space, and the optimal number of assemblages was determined by the Calinski-Harabasz criterion (Calinski \& Harabasz, 1974). Clustering the taxa into assemblages and using the Hellinger transformation decreased some of the remaining sampling bias, such as fishing a school of one taxon in a given year. Analyzing the outputs of STATICO at the level of taxa assemblages instead of that of the taxa themselves also mitigated this kind of bias. To determine which environmental variables had the strongest relations with assemblages, we calculated Spearman correlation coefficients between annual mean compromise scores for taxa assemblages and the environmental variables.

Depth was correlated to bottom trawl (Spearman's rho=-0.46, p-value $<2.2 \mathrm{e}-16$ ), pelagic trawl (Spearman's rho $=0.36$, p-value $<2.2 \mathrm{e}-16$ ) and bottom temperature (Spearman's rho $=0.60$, p-value $<2.2 \mathrm{e}-16$ ). However, the STATICO approach does not allow partialling out the effects of the variables, notably the ones that do not vary with time (i.e. depth and sediment type). To evaluate the importance of stable environmental variables in the taxa-environment relation, we clustered sampling sites into strata according to depth and sediment type, using k-means clustering on Euclidean distance, determining the number of clusters according to the Calinski-Harabasz criterion. We analyzed temporal changes in taxa-environment relations for each stratum following Kidé et al. (2015). Indicator taxa for each site stratum were calculated based on the IndVal Species Indicator Value (Dufrêne \& Legendre, 1997). For each indicator taxa, we identified its associated assemblage determined from the clustering of the STATICO compromise space. All statistical analyses were conducted in R (R Core Team, 2019).

\section{RESULTS}

\section{Interstructure analysis}

The interstructure analysis measured the resemblance between the years in the relationship between taxa and the environmental variables (Fig. 2). The first axis of the interstructure space explained $70.8 \%$ of the correlations between years, and its second axis explained $18.1 \%$ (Fig. $2 \mathrm{a}$ ). The similar length of arrows in the correlation circle indicated relative stability in the relation between taxa and the environment over the years (Fig. 2b). Nonetheless, some values of vectorial 
correlation coefficients $R v$ were moderate, indicating that some relations between taxa and environmental variables did vary for some years (Fig. 2c). The second axis of the interstructure distinguished two main periods: 2000-2002 and 2003-2016, the second of which could be subdivided into the periods 2003-2009 and 2010-2016 (Fig. 2b).

\section{Compromise analysis}

The compromise analysis informed on the temporally stable part of the relationships between the taxa and the environmental variables. The first principal component of the compromise space, which explained $56.8 \%$ of total variation in the compromise space, was associated with depth, bottom temperature and pelagic trawl effort in its positive half and chlorophyll a and bottom trawl effort in its negative half (Fig. 3a). The second principal component explained $7.7 \%$ of total variation and was associated mostly with sediment type and bottom temperature (Fig. 3a).

Clustering of taxa scores on the first two axes of the compromise space yielded six assemblages (Fig. 3b, Appendix 4). Assemblage \#1 lay near the center of the compromise space, with no distinct patterns, and is thus composed of generalist taxa. The biomass of this assemblage was dominated by mackerel Scomber scombrus and poor cod Trisopterus minutus. Assemblage \#2, in deeper areas, was associated with warm bottom temperature, high pelagic trawl effort, coarse sediments, low chlorophyll a concentration and low bottom trawl effort. Boarfish Capros aper, horse mackerel Trachurus trachurus and blue whiting Micromesistius poutassou had the largest biomass in this assemblage. Conversely, assemblage \#3 was associated with shallow-to-medium depth, high chlorophyll a concentration, medium-high bottom trawl effort, low bottom temperature and low pelagic trawl effort. Atlantic herring Clupea harengus and grey gurnard Eutrigla gunardus had the largest biomass in this assemblage. Assemblages \#1 and \#3 contained more planktivorous species than the other assemblages. Assemblage \#4 was found in environmental conditions similar to those of assemblage \#2, but over finer sediments and in areas with colder bottom temperature. Shortfin squid Illex coindeti and megrim Lepidorhombus whiffiagonis had the largest biomass in this assemblage. Assemblage \#5 was found in environmental conditions similar to those of assemblage \#3, but with higher chlorophyll a concentration and higher bottom trawl effort. Commercial fish essentially dominated the biomass of this assemblage: haddock Melanogrammus aeglefinus, whiting Merlangius merlangus, small-spotted catshark Scyliorhinus canicula and Norway pout Trisopterus esmarkii. Assemblage \#6 also contained commercially 
important species, such as hake Merluccius merluccius, cod Gadus morhua, nephrops Nephrops norvegicus and American plaice Hippoglossoides platessoides, which were found in environmental conditions similar to those of assemblage \#3, but over finer sediments and in areas with colder bottom temperature.

\section{Intrastructure - Variation in the relative importance of structuring variables over 17 years}

Overall, depth, chlorophyll a and temperature structured axis 1 the most for the entire time series (i.e. lay furthest from the center of the compromise space). The structuring effect of depth, sediment type and temperature remained relatively stable over the years (i.e. small ellipses) (Fig. 4a). Conversely, chlorophyll a, bottom trawl effort and pelagic trawl effort varied most over the years (i.e. the largest ellipses) (Fig. 4b).

The structuring effect of bottom trawl effort on assemblages was strong in 2000, decreased slightly after 2002 and was weak from 2009-2016 (axis 1, Fig. 4a,b). Bottom trawl effort was exerted in area characterized by shallow depth with cold temperature, fine sediments and high chlorophyll a concentration from 2000-2002, then in area with less marked characteristics from 2002-2009. From 2010-2011, its association shifted toward greater depth and warmer temperature, after which it had less structuring effect (Fig. 4a,b).

Pelagic trawl effort had little structuring effect from 2000-2003 but was as important as depth, chlorophyll a and temperature from 2005-2008. After 2009, its structuring effect decreased strongly (Fig. 4b). Pelagic trawl effort was associated with great depth, warm temperature and low chlorophyll a concentration from 2005-2008 and again in 2012. Lastly, chlorophyll a had a strong structuring effect (especially in 2007 and 2011), except in 2003 and in 2013 (Fig. 4b). Temperature was particularly important in 2008 and 2010. After 2009, assemblages were thus driven essentially by depth, chlorophyll a and temperature.

The interpretation of the variations in the link with taxa biomass of depth and sediments, which values do not change over time, was not straightforward. Either the sampling was performed from significantly different sediment types and depths over the years, or taxa moved throughout the Celtic Sea, which would also have changed their relations with sediment type and depth. Since neither sampling depth nor sediment type differed significantly among years (Kruskal-Wallis Chi-squared $=10.88$ and 37.83, respectively; $\mathrm{p}$-value $=0.82$ and 0.99 , respectively), annual variations in the relations between taxa and sediment type or depth were most likely explained by the taxa moving among different sediment types and depths. 
Intrastructure - temporal variability in assemblages in relation to environmental variables

Taxa maintained stable relations with the environment over the years (i.e. small ellipses in Fig. 4c,d). Assemblage \#1 had less variation around its mean position in the compromise space over the years than the other assemblages. Conversely, assemblage \#5 varied the most (i.e. had the largest ellipse) and overlapped assemblage \#3. These two assemblages co-varied positively with chlorophyll a concentration with no time lag (Table 1). When chlorophyll a had a strong structuring effect, the ellipses of these two assemblages also expanded toward higher chlorophyll a concentration in the compromise space. Conversely, when chlorophyll a had a strong structuring effect, assemblage \#2 was associated with low chlorophyll a concentration. When pelagic trawl effort had a strong structuring effect, however, assemblage \#2 was associated with high pelagic trawl effort, while assemblage \#3 was associated with low pelagic trawl effort.

\section{Spatio-temporal variability in assemblages and environmental variables}

Sampling sites were clustered into four strata based on depth and sediment type. Stratum 1 consisted of a few sites (56) along the deepest border of the area (235-339.5 m deep) (Fig. 5) and was located in the part of the compromise space related to great depth, but also to warm bottom temperature and high pelagic trawl effort. There was no clear match between environmental and taxa trajectories at these sites (Fig. 6); thus, taxa at these sites were most likely influenced by other sources of variability than the environmental variables considered here. Stratum 2 consisted of shallower sites (155-229 $\mathrm{m}$ deep), also along the deepest border of the area, but with warmer bottom temperature and higher pelagic trawl effort than those of stratum 1. From 2001-2008 and 2012-2014, similar temporal variations between environmental variables and taxa suggested that variations in taxa biomass were related to dynamics of the environmental variables used in this study. From 2001-2008, pelagic trawl effort was most likely an important driver of assemblages at these sites, since it was an important driver of assemblages overall during this period and was exerted at these sites (Fig. 6 and 7a). Stratum 3 consisted of sites in the center of the Celtic Sea, where environmental and taxa trajectories showed the same move from the left to the right of the compromise space in 2006-2007 and 2009-2011, and then from the right to the left in 2007-2009 and 2011-2013 (Fig. 6). These trajectories were most likely related to a relative increase in bottom temperature at these sites from 2006-2007 (Fig. 8a and Appendix 2, Fig. S3). From 2007-2009, the similar dynamics of environment and taxa were driven by a decrease in bottom temperature and a 
slight increase in chlorophyll a and bottom trawl effort in this stratum. From 2011-2013, a similar move toward the left of the compromise space was driven by a distinct decrease in mean bottom temperature (Fig. 6 and 8a). Finally, stratum 4 consisted of coastal sites and was located in the part of the compromise space related to high chlorophyll a concentration and high bottom trawl effort. Environmental trajectories of this stratum had a larger amplitude than those of the other strata (yaxis ranges in Fig. 6), which indicates the higher variability in this environment. These sites had similar trends from 2005-2009, but the dynamics were difficult to relate to variation in a particular environmental variable (Fig. 7, 8 and Appendix 2, Fig. S1 and S4). In addition, these sites are located in the part of the Celtic Sea where increase in bottom temperature has been the highest $\left(+0.04^{\circ} \mathrm{C} / \mathrm{y}\right)($ Fig. $8 \mathrm{~b})$.

For each stratum, we determined indicator taxa with the IndVal Species Indicator Value, which are the taxa found most often in that stratum, at all of its sites. The indicator taxa of strata 1 and 2, located on the deep border of the Celtic Sea, belonged to assemblages \#4 and \#2, respectively (Table 2), since these assemblages are found in the deepest part of the area (Fig. 2). Sites in stratum 3 (center of the Celtic Sea) hosted mixed assemblages since they had only one indicator taxon, poor cod Trisopterus minutus, which belonged to the generalist assemblage \#1. Stratum 4 (coastal sites) consisted of indicator taxa that belonged to assemblages \#3 and \#5. Taxa from assemblages \#1 and \#6 were the indicator taxa of multiple strata. These assemblages had no distinct spatial distribution. Indicator taxa in a given stratum did not necessarily belong to the same assemblage and thus did not necessarily vary in the same way with the environment.

\section{DISCUSSION}

We investigated spatio-temporal dynamics of co-variations between the environment and taxa to determine whether the main environmental and anthropogenic trends in ecosystems in the Celtic Sea had influenced the biomass of taxa. Namely, if the reduced fishing mortality after the mid 90's (ICES, 2018b) has continued to shape the structure of the assemblage during a warmer regime since 2002. We distinguished six assemblages that illustrate different types of responses to environmental and fishing variables in the Celtic Sea and highlighted an overall stable relation between taxa and the environment over time. From 2000-2016, depth, chlorophyll a and bottom temperature were the main variables structuring assemblages in the Celtic Sea. In particular, we 
identified a relation between assemblages \#2, \#3 and \#5 and chlorophyll a throughout the time series, highlighting a strong bottom-up influence for these assemblages.

Over the period studied, bottom and pelagic trawl efforts were less important than depth, chlorophyll a and temperature in structuring the assemblages. This finding echo the work of ter Hofstede et al. (2010) on species richness, who concluded that climate likely influenced species richness in the Celtic Sea more than fisheries did. The Celtic Sea has been intensively fished since the 1950s and thus has adapted to this driver, reaching a new steady state. The main shift in the Celtic Sea probably occurred before the 1980s, as indicated by a decrease in trophic levels (Guénette \& Gascuel, 2012). Along the gradient of fishing effort, the most common effect of fishing documented on community structure is the removal of apex predators (Ellingsen et al., 2015; Stortini, Frank, Leggett, Shackell, \& Boyce, 2018). Here, we investigate a period of relatively stable fishing scenario following a sharp increase (Guénette \& Gascuel, 2012; ICES, 2018b); so no large shift resulting from the removal of a top predator was visible at the scale of our time series. Nevertheless, the level of fishing pressure in the Celtic Sea remains high, with only $29 \%$ of the stocks fished below the $\mathrm{F}_{\mathrm{MSY}}$ (ICES, 2018b). Conversely, fishing seems to be the dominant driver of Northwest Atlantic ecosystems (Shackell, Bundy, Nye, \& Link, 2012). This is most likely caused by the time series considered (1970-2008) compare to the one studied here (2000-2016).

Despite this overall stability, the relative importance of some structuring variables did change. In particular, bottom and pelagic trawl efforts had little effect on community composition after 2009, perhaps due to bottom trawl effort moving to deeper areas, thus sharply decreasing in coastal areas (Fig. 7b and Appendix 2, Fig. S4). This spatial movement of bottom trawl effort corresponds to a shift from targeting mostly nephrops Nephops norvegicus and whitefish species (Merlangius merlangus, Melanogrammus aeglefinus) to a larger share of anglerfish (Lophius piscatorius and Lophius budegassa) (Appendix 3, Fig. S7). For the taxa landed most often, pelagic trawl effort shifted after 2007 from horse mackerel Trachurus trachurus to boarfish Caproidae (Appendix 3, Fig. S9). This change in targeted taxa could explain the decreased importance of fishing in structuring assemblages by shifting toward targeted taxa that do not co-vary with fishing effort.

Conversely, some environmental variables varied in their value but not in their structuring effect. For example, bottom temperature had an important and relatively stable structuring effect 
despite increasing by $0.04{ }^{\circ} \mathrm{C} / \mathrm{y}$ from 2000-2016 in the northern Celtic Sea. Assemblages \#3, \#5 and especially \#6, whose taxa co-varied negatively with bottom temperature, clearly differed from assemblage \#2, whose taxa co-varied positively with bottom temperature. This difference may be related to the location of the Celtic Sea at the biogeographical boundary between warm-water Lusitanian taxa and cold-water boreal taxa (Ellis, Martinez, Burt, \& Scott, 2013; Hátún et al., 2009). Assemblages \#3, \#5 and \#6 contained commercially important taxa such as Atlantic herring Clupea harengus (\#3), haddock Melanogrammus aeglefinus (\#5), whiting Merlangius merlangus (\#5), cod Gadus morhua (\#6) and the American plaice Hippogloissoides platessoides (\#6). These taxa may move northward in the coming years to avoid the increase in bottom temperature, which could change Celtic Sea communities and eventually fisheries. A similar northward movement was documented along the western coast of Scotland (ter Hofstede et al., 2010) of fish species considered to be cold-water boreal by Yang (1982). In addition, taxa from these assemblages may become less common in the Celtic Sea due to the predicted decrease in chlorophyll a concentration caused by climate change (Henson et al., 2010). Assemblage \#2 contained warm-water taxa from the Bay of Biscay (Hátún et al., 2009), such as boarfish Capros aper, that have already begun and may continue to become more numerous and dominant in biomass due to the increase in temperature (Coad et al. 2014). Indeed, the number of warm-water species in the Celtic Sea has already increased (ter Hofstede et al., 2010), which makes it an area of special interest for studying potential replacement of cold-water taxa by warm-water taxa.

To characterize further the potential response of taxa to changes in environmental variables, a local scale must be considered. The more coastal sites in the northern Celtic Sea hosted taxa in assemblages \#3 and \#5 that co-varied negatively with temperature: whiting Merlangius merlangus, dab Limanda limanda, Norway pout Trisopterus esmarkii, sprat Sprattus sprattus, plaice Pleuronectes platessa, Atlantic herring Clupea harengus, haddock Melanogrammus aeglefinus, spotted ray Raja montagui, lemon sole Microstomus kitt and American plaice Hippoglossoides platessoides. Bottom temperature has increased the most in coastal areas (Fig. 8b), however, making these taxa susceptible to a decrease in biomass in the Celtic Sea. In addition, taxa located along the deepest border of the Celtic Sea, which co-varied positively with pelagic trawl effort throughout the time series, appeared to respond most to pelagic trawl effort from 2001-2008, which could reveal adaptation of the pelagic trawlers targeting taxa in this area. This response could help explain the spatial heterogeneity in taxa distribution already observed in the Celtic Sea (Dolder, Thorson, \& Minto, 2018). 
Despite overall stability of the relation between taxa and the environment in the Celtic Sea, variation in bottom temperature and bottom trawl effort showed spatial heterogeneity. Depending on the area considered, the environment and taxa did not always have the same trajectory over time. This difference highlights the complex influence of space and of the variables considered (i.e. chlorophyll a, bottom temperature, and bottom and pelagic trawl efforts). In addition, variables not considered in this study, such as salinity or current, could explain some variations in taxa biomass for the years with no visible match. Time lags not captured by the annual mean can also influence taxa dynamics. Long-lived taxa that feed on small fish can be influenced by variations in phytoplankton abundance over much longer timescales than the few days necessary to trigger a reaction in phytoplankton dynamics (Sharples et al., 2013). Larger-scale spatial patterns, such as the NAO or AMO, are also likely to influence these assemblages. The NAO warm phase results in more frequent storms and precipitation in northern Europe. Since the late 1990s, this difference in atmospheric pressure has remained close to the average, except for a sharp decrease in 2010 (Edwards et al., 2013; Hátún et al., 2009; Hurrell, Kushnir, Ottersen, \& Visbeck, 2003). The change in taxa' trajectories of strata could be related to the decrease in temperatures observed in 2011-2013 in the central Celtic Sea. In comparison, the AMO influences sea surface temperature and has a longer period of $c a$. 60-80 years. It has been in a positive phase since 1995, which is associated with warmer sea surface temperatures. It influences marine ecosystem dynamics strongly and, in particular, promotes growth of sardine Sardina pilchardus populations during its warm phases and Atlantic herring Clupea harengus populations during its cold phases (Edwards et al., 2013). These climatic phenomena superimpose their influences on global warming due to climate change, making it challenging to determine the relative influences of the AMO, NAO and global warming on the increase in temperature observed in the northern Celtic Sea. They have a complex influence on biological systems, which renders inference of their direct effects on taxa uncertain (Beaugrand, 2012). For these reasons, we focused only on regional variables whose influence on taxa could be identified.

Our integrated analysis enabled investigating spatio-temporal co-variations of taxa and the environment in a single analysis over 17 years for a large dataset of 101 taxa and six environmental variables. It summarized ecosystem dynamics to form assemblages of taxa with similar responses to environmental variations, which provided information about the most important structuring variables and average relations between taxa and the environment. Its strength lies in its ability to consider variations in the relations between taxa and the environment 
at different temporal and spatial scales, making the analysis an adaptive tool, and to study the relative effects of several environmental drivers. However, this statistical approach does not enable partialling out the effect of each variable.

Although the Celtic Sea is exploited greatly, its biotic assemblages are influenced mainly by depth, bottom temperature and chlorophyll a concentration. Indeed, only assemblage \#3 significantly co-varied negatively with pelagic trawl effort. This result is consistent with that of Kidé et al. (2015), who analyzed the predominant role of chlorophyll a and sea surface temperature in structuring the ecosystem of another exploited fishing ground along the Mauritanian shelf. Studies at the ecosystem scale provide information about the relative importance of fishing effort as a structuring variable of ecosystems, which is necessary in the context of implementing more sustainable fishing practices. In the context of global warming, the response of commercial species to increased temperature also receives a great deal of attention, due to their potential changes in distribution and the resulting impacts on fisheries (Cheung, Watson, \& Pauly, 2013). However, studies of the responses of a large number of species (i.e. commercial and non-commercial species) to simultaneous impacts of fishing effort and global warming remain scarce (but see Shackell, Bundy, Nye, \& Link, 2012). In this study, we provided information about effects of variation in the spatial distribution of bottom and pelagic trawl effort in the Celtic Sea and the decrease in the importance of these two practices as structuring variables of communities after 2009. This study also provided information about the relative importance of fishing effort to the macro bentho-demersal diversity of an exploited fishing ground. Slight changes in the spatial distribution of fishing effort and the taxa targeted are thus likely to reduce the structuring effect of fishing effort on the entire ecosystem. Increased bottom temperature in the Celtic Sea has not yet changed assemblages of taxa but is likely to trigger substantial changes in their distributions in the coming years, especially cold-water commercial taxa such as hake, cod, nephrops and American plaice. These results could help select which species should have their dynamics simulated under variations in several environmental and fishing variables at the same time to provide information useful for managers and scientists.

\section{ACKNOWLEDGEMENT}

We thank all those who made data sampling possible during the EVHOE surveys.

\section{DATA SHARING AND DATA ACCESSIBILITY}


The data that support the findings of this study are available in DATRAS ICES at https://datras.ices.dk/Data_products/Download/Download_Data_public.aspx.

\section{REFERENCES}

Beaugrand, G. (2012). Unanticipated biological changes and global warming. Marine Ecology Progress Series, 445, 293-301. https://doi.org/10.3354/meps09493

Beisner, B. E., Haydon, D. T., \& Cuddington, K. (2003). Alternative stable states in ecology. Frontiers in Ecology and the Environment, 1(7), 376-382. https://doi.org/10.1890/15409295(2003)001[0376:ASSIE]2.0.CO;2

Belkin, I. M. (2009). Rapid warming of Large Marine Ecosystems. Progress in Oceanography, 81(1-4), 207-213. https://doi.org/10.1016/j.pocean.2009.04.011

Calinski, T., \& Harabasz, J. (1974). A dendrite method for cluster analysis. Communication in Statistics, 3(1), 1-27. Retrieved from www.bogucki.com.pl,

Cheung, W. W. L., Watson, R., \& Pauly, D. (2013). Signature of ocean warming in global fisheries catch. Nature, 497(7449), 365-368. https://doi.org/10.1038/nature12156

Coad, J. O., Hussy, K. ., Farrell, E. D., \& Clarke, M. W. (2014). The recent population expansion of boarfish, Capros aper (Linnaeus, 1758): interactions of climate, growth and recruitment. Applied Ichthyology, 30, 463-471. https://doi.org/10.1111/jai.12412

deYoung, B., Barange, M., Beaugrand, G., Harris, R., Perry, R. I., Scheffer, M., \& Werner, F. (2008). Regime shifts in marine ecosystems: detection, prediction and management. Trends in Ecology and Evolution, 23(7), 402-409. https://doi.org/10.1016/j.tree.2008.03.008

Dolder, P. J., Thorson, J. T., \& Minto, C. (2018). Spatial separation of catches in highly mixed fisheries. Scientific Reports, 8(1), 1-11. https://doi.org/10.1038/s41598-018-31881-w

Dufrêne, M., \& Legendre, P. (1997). Species assemblages and indicator species: The need for a flexible asymmetrical approach. Ecological Monographs, 67(3), 345-366.

https://doi.org/10.2307/2963459

Dulvy, N. K., Rogers, S. I., Jennings, S., Stelzenmüller, V., Dye, S. R., \& Skjoldal, H. R. (2008). Climate change and deepening of the North Sea fish assemblage: A biotic indicator of warming seas. Journal of Applied Ecology, 45(4), 1029-1039. https://doi.org/10.1111/j.13652664.2008.01488.x

Edwards, M., Beaugrand, G., Alheit, J., Helaouët, P., \& Coombs, S. (2013). Marine Ecosystem Response to the Atlantic Multidecadal Oscillation. PLoS ONE, 8(2), e57212. 
https://doi.org/10.1371/journal.pone.0057212

Ellingsen, K. E., Anderson, M. J., Shackell, N. L., Tveraa, T., Yoccoz, N. G., \& Frank, K. T. (2015). The role of a dominant predator in shaping biodiversity over space and time in a marine ecosystem. Journal of Animal Ecology, 84(5), 1242-1252.

https://doi.org/10.1111/1365-2656.12396

Ellis, J. R., Martinez, I., Burt, G. J., \& Scott, B. E. (2013). Epibenthic assemblages in the Celtic Sea and associated with the Jones Bank. Progress in Oceanography, 117, 76-88. https://doi.org/10.1016/j.pocean.2013.06.012

Fabry, V. J., Seibel, B. A., Feely, R. A., \& Orr, J. C. (2008). Impacts of Ocean Acidification on Marine Biodiversity. ICES Journal of Marine Science, 65, 414-432. https://doi.org/10.2307/j.ctv8jnzw1.25

Fernandes, P. G., \& Cook, R. M. (2013). Reversal of fish stock decline in the northeast atlantic. Current Biology, 23(15), 1432-1437. https://doi.org/10.1016/j.cub.2013.06.016

Fossheim, M., Primicerio, R., Johannesen, E., Ingvaldsen, R. B., Aschan, M. M., \& Dolgov, A. V. (2015). Recent warming leads to a rapid borealization of fish communities in the Arctic. Nature Climate Change, 5(7), 673-677. https://doi.org/10.1038/nclimate2647

Foveau, A., Vaz, S., Desroy, N., \& Kostylev, V. E. (2017). Process-driven and biological characterisation and mapping of seabed habitats sensitive to trawling. PLOS ONE, 12(10), 130. https://doi.org/10.1371/journal.pone.0184486

Garcia, S. M. M., Zerbi, A., Aliaume, C., Do Chi, T., \& Lasserre, G. (2003). The ecosystem approach to fisheries. FAO Fisheries Technical Paper (Vol. 443).

https://doi.org/10.1111/j.1467-2979.2010.00358.x

Griggs, D. J., Nilsson, M., Stevance, A., \& McCollum, D. (2017). A Guide To SDG Interactions : From Science to implementation. https://doi.org/DOI: 10.24948/2017.01 ICSU

Guénette, S., \& Gascuel, D. (2012). Shifting baselines in European fisheries: The case of the Celtic Sea and Bay of Biscay. Ocean and Coastal Management, 70, 10-21. https://doi.org/10.1016/j.ocecoaman.2012.06.010

Hátún, H., Payne, M. R., Beaugrand, G., Reid, P. C., Sandø, A. B., Drange, H., ... Hansen, B. (2009). Large bio-geographical shifts in the north-eastern Atlantic Ocean: From the subpolar gyre, via plankton, to blue whiting and pilot whales. Progress in Oceanography, 80, 149162. https://doi.org/10.1016/j.pocean.2009.03.001

Henson, S. A., Sarmiento, J. L., Dunne, J. P., Bopp, L., Lima, I., Doney, S. C., .. Beaulieu, C. 
(2010). Detection of anthropogenic climate change in satellite records of ocean chlorophyll and productivity. Biogeosciences, 7(2), 621-640. https://doi.org/10.5194/bg-7-621-2010

Hurrell, J. W., Kushnir, Y., Ottersen, G., \& Visbeck, M. (2003). An overview of the north atlantic oscillation. Geophysical Monograph Series, 134, 1-35. https://doi.org/10.1029/134GM01

ICES. (2015). Report of the International Bottom Trawl Survey Working Group (IBTSWG) 23-27 March 2015. Bergen, Norway: ICES CM 2015/SSGIEOM: 24. 278pp.

ICES. (2018a). Celtic Seas Ecoregion. In ICES Ecosystem Overviews (ICES, pp. 1-17). https://doi.org/10.17895/ices.pub.4667

ICES. (2018b). ICES Fisheries Overviews Celtic Seas Ecoregion. ICES Advice 2018, (November), 1-37. https://doi.org/10.17895/ices.pub.4640

IPCC. (2014). Climate Change 2014 Part A: Global and Sectoral Aspects. Contribution of Working Group II to the Fifth Assessment Report of the Intergovernmental Panel on Climate Change. (C. B. Field, V. R. Barros, D. J. Dokken, K. J. Mach, M. D. Mastrandrea, T. E. Bilir, ... L. L. White, Eds.) (Cambridge). Cambridge, United Kingdom and New York, NY, USA. Retrieved from papers2://publication/uuid/B8BF5043-C873-4AFD-97F9-A630782E590D

Jönsson, B. F., Salisbury, J. E., \& Mahadevan, A. (2011). Large variability in continental shelf production of phytoplankton carbon revealed by satellite. Biogeosciences, 8(5), 1213-1223. https://doi.org/10.5194/bg-8-1213-2011

Karakassis, I., \& Eleftheriou, A. (1997). The continental shelf of Crete: Structure of macrobenthic communities. Marine Ecology Progress Series, 160, 185-196. https://doi.org/10.3354/meps 160185

Kidé, S. O., Manté, C., Dubroca, L., Demarcq, H., \& Mérigot, B. (2015). Spatio-temporal dynamics of exploited groundfish species assemblages faced to environmental and fishing forcings: Insights from the mauritanian exclusive economic zone. PLoS ONE, 10(10), 1-21. https://doi.org/10.1371/journal.pone.0141566

Le Bris, A., Mills, K. E., Wahle, R. A., Chen, Y., Alexander, M. A., Allyn, A. J., .. Pershing, A. J. (2018). Climate vulnerability and resilience in the most valuable North American fishery. Proceedings of the National Academy of Sciences of the United States of America, 115(8), 1831-1836. https://doi.org/10.1073/pnas.1711122115

Martinez, I., Ellis, J. R., Scott, B., \& Tidd, A. (2013). The fish and fisheries of Jones Bank and the wider Celtic Sea. Progress in Oceanography, 117, 89-105. https://doi.org/10.1016/j.pocean.2013.03.004 
Mateo, M., Pawlowski, L., \& Robert, M. (2017). Highly mixed fisheries: Fine-scale spatial patterns in retained catches of French fisheries in the Celtic Sea. ICES Journal of Marine Science, 74(1), 91-101. https://doi.org/10.1093/icesjms/fsw129

McLean, M. J., Mouillot, D., Goascoz, N., Schlaich, I., \& Auber, A. (2018). Functional reorganization of marine fish nurseries under climate warming. Global Change Biology, (October), 1-15. https://doi.org/10.1111/gcb.14501

Pauly, D., Christensen, V., Guénette, S., Pitcher, T. J., Sumaila, U. R., Walters, C. J., ... Zeller, D. (2002). Towards sustainability in World Fisheries. Nature, 418(August), 689-695. https://doi.org/10.1038/nature01017

Planque, B., Fromentin, J. M., Cury, P., Drinkwater, K. F., Jennings, S., Perry, R. I., \& Kifani, S. (2010). How does fishing alter marine populations and ecosystems sensitivity to climate? Journal of Marine Systems, 79(3-4), 403-417. https://doi.org/10.1016/j.jmarsys.2008.12.018

Quero, J. C., Du Buit, M. H., \& Vayne, J. J. (1998). Les observations de poissons tropicaux et le rechauffement des eaux dans l'Atlantique europeen. Oceanologica Acta, 21(2), 345-351. https://doi.org/10.1016/S0399-1784(98)80021-2

R Core Team. (2019). R: A Language and Environment for Statistical Computing. R Foundation for Statistical Computing. Vienna, Austria. https://doi.org/10.1007/978-3-540-74686-7

Rao, C. R. (1995). A review of canonical coordinates and an alternative to correspondence analysis using Hellinger distance. Questiio. Retrieved from http://upcommons.upc.edu/handle/2099/4059

Shackell, N. L., Bundy, A., Nye, J. A., \& Link, J. S. (2012). Common large-scale responses to climate and fishing across Northwest Atlantic ecosystems. ICES Journal of Marine Science, 69(2), 151-162. https://doi.org/10.1093/icesjms/fsr195

Sharples, J., Ellis, J. R., Nolan, G., \& Scott, B. E. (2013). Fishing and the oceanography of a stratified shelf sea. Progress in Oceanography, 117, 130-139.

https://doi.org/10.1016/j.pocean.2013.06.014

Simier, M., Blanc, L., Pellegrin, F., \& Nandris, D. (1999). Approche simultanée de K couples de tableaux : application à l'étude des relations pathologie végétale - environnement. Revue de Statistique Appliquée, 47(1), 31-46.

Sotillo, M. G., Cailleau, S., Lorente, P., Levier, B., Aznar, R., Reffray, G., ... Alvarez-Fanjul, E. (2015). The myocean IBI ocean forecast and reanalysis systems: Operational products and roadmap to the future copernicus service. Journal of Operational Oceanography, 8(1), $63-$ 
79. https://doi.org/10.1080/1755876X.2015.1014663

Stortini, C. H., Frank, K. T., Leggett, W. C., Shackell, N. L., \& Boyce, D. G. (2018). Support for the trophic theory of island biogeography across submarine banks in a predator-depleted large marine ecosystem. Marine Ecology Progress Series, 607, 155-169.

https://doi.org/10.3354/meps 12799

ter Hofstede, R., Hiddink, J., \& Rijnsdorp, A. (2010). Regional warming changes fish species richness in the eastern North Atlantic Ocean. Marine Ecology Progress Series, 414, 1-9. https://doi.org/10.3354/meps08753

Thioulouse, J., Simier, M., \& Chessel, D. (2004). Simultaneous analysis of a sequence of paired ecological tables with the $\{$ STATICO $\}$ method. Ecology, 85(1), 272-283. https://doi.org/10.1890/02-0605

Thioulouse, Jean, Dray, S., Dufour, A.-B., Siberchicot, A., Jombart, T., \& Pavoine, S. (2018). Multivariate Analysis of Ecological Data with ade4. Springer.

Thomson, J. A., Burkholder, D. A., Heithaus, M. R., Fourqurean, J. W., Fraser, M. W., Statton, J., \& Kendrick, G. A. (2015). Extreme temperatures, foundation species, and abrupt ecosystem change: an example from an iconic seagrass ecosystem. Global Change Biology, 21(4), 1463-1474. https://doi.org/10.1111/gcb.12694

Tucker, L. R. (1966). Some mathematical notes on three-mode factor analysis. Psychometrika, 31(3), 279-311. Retrieved from http://www.ncbi.nlm.nih.gov/pubmed/6131560

Vaz, S., Carpentier, A., \& Coppin, F. (2007). Eastern English Channel fish assemblages: Measuring the structuring effect of habitats on distinct sub-communities. ICES Journal of Marine Science, 64(2), 271-287. https://doi.org/10.1093/icesjms/fs1031

Wakelin, S. L., Artioli, Y., Butenschön, M., Allen, J. I., \& Holt, J. T. (2015). Modelling the combined impacts of climate change and direct anthropogenic drivers on the ecosystem of the northwest European continental shelf. Journal of Marine Systems, 152, 51-63. https://doi.org/10.1016/j.jmarsys.2015.07.006

Yang, J. (1982). The dominant fish fauna in the North Sea and its determination. Journal of Fish Biology, 20(6), 635-643. https://doi.org/10.1111/j.1095-8649.1982.tb03973.x 


\section{TABLES}

Table 1. Spearman correlation coefficients between yearly averaged scores of taxa and environmental variables on the first axis of the compromise space for each assemblage. ${ }^{*} p<$ 0.05 .

\begin{tabular}{ccccccc}
\hline & $\begin{array}{c}\text { Bottom trawl } \\
\text { effort }\end{array}$ & $\begin{array}{c}\text { Chlorophyll } \\
\mathrm{a}\end{array}$ & Depth & $\begin{array}{c}\text { Pelagic trawl } \\
\text { effort }\end{array}$ & $\begin{array}{c}\text { Sediment } \\
\text { type }\end{array}$ & $\begin{array}{c}\text { Bottom } \\
\text { temperature }\end{array}$ \\
\hline 1 & 0.069 & 0.137 & -0.047 & 0.105 & 0.483 & 0.444 \\
2 & 0.086 & $-0.561^{*}$ & 0.407 & $0.505^{*}$ & -0.272 & 0.348 \\
3 & -0.017 & $0.806^{*}$ & $-0.630^{*}$ & $-0.618^{*}$ & 0.275 & 0.010 \\
4 & -0.147 & -0.360 & 0.358 & 0.051 & -0.059 & 0.397 \\
5 & -0.319 & $0.919^{*}$ & $-0.821^{*}$ & -0.350 & 0.453 & -0.125 \\
6 & 0.000 & 0.360 & -0.225 & -0.434 & 0.282 & 0.113 \\
\hline
\end{tabular}

Table 2. Correspondence between indicator taxa of geographical strata based on depth and sediment type and those of assemblages defined in the compromise space of STATICO (Fig. 2b). Scientific names corresponding to taxa codes can be found in Appendix 1. Taxa are ordered by decreasing values of IndVal Species Indicator Value index in each stratum.

\begin{tabular}{|c|c|c|}
\hline Taxon code & $\begin{array}{l}\text { Depth and } \\
\text { sediment- } \\
\text { based stratum }\end{array}$ & $\begin{array}{l}\text { STATICO } \\
\text { assemblage }\end{array}$ \\
\hline HELIDAC & \multirow{10}{*}{1} & 4 \\
\hline ARGE & & 2 \\
\hline ILLECOI & & 4 \\
\hline MOLVMAC & & 4 \\
\hline LEPIBOS & & 4 \\
\hline MUNI & & 4 \\
\hline MALCLAE & & 4 \\
\hline GADIARG & & 4 \\
\hline TODIEBL & & 2 \\
\hline LEPIWHI & & 4 \\
\hline
\end{tabular}




\begin{tabular}{|lll}
\hline MERLMER & 6 \\
\cline { 2 - 3 } ARNO & 2 \\
\hline CHELCUC & 2 \\
\hline SEPIORB & 2 \\
\hline ZEUSFAB & 2 \\
\hline TRISMIN & 3 & 1 \\
\hline MERNMER & 5 \\
\hline EUTRGUR & 3 \\
\hline LIMDLIM & 5 \\
\hline TRISESM & 5 \\
\hline SPRASPR & 3 \\
\hline PLEUPLA & 5 \\
\hline CLUPHAR & 3 \\
ALLO & 5 \\
\hline CALMLYR & 4 & 5 \\
MELAAEG & 5 \\
\hline SOLESOL & 5 \\
\hline RAJAMON & 5 \\
SCYOCAN & 5 \\
\hline MAJABRA & 5 \\
\hline MICTKIT & 5 \\
\hline SCOMSCO & 5 \\
\hline
\end{tabular}

\section{FIGURES LEGENDS}

Fig 1. Map of the study area (bounded by the red line) and the 1175 sampling sites used (black dots) 
Fig 2. Interstructure analysis. (a) Eigenvalues of the Rv matrix (vectorial correlation in taxaenvironment co-variances between two years), (b) correlation circle with scores for years, and (c) histogram of all pairwise $R v$ values.

Fig 3. Compromise analysis. (a) Scores of the environmental variables. Parameter $d$ shows the scale of the plot (width of a grid square). (b) Scores of the taxa clustered into six assemblages using k-means clustering. Taxa with the largest biomass in each assemblage are listed in the legend and displayed as silhouettes. Scientific names corresponding to taxa codes can be found in Appendix 1.

Fig 4. Intrastructure plots with (a) annual positions of environmental variables, (b) circles proportional to scores of the environmental variables on axis 1, (c) annual positions of taxa assemblages obtained after $k$-means clustering, and (d) circles proportional to scores of the assemblages on axis 1. Ellipses on plots (a) and (c) summarize the clouds of dots (years) weighted by their distance to the center of the ellipses (mean position over the years).

Fig 5. Sampling sites in the Celtic Sea clustered based on depth and sediment type into four strata.

Fig 6. Trajectory factor maps - projection of the four strata, clustered based on depth and sediment type, as supplementary elements in both factorial maps (environmental variables and taxa) of the principal component analysis of the compromise space: (a) Overview of the position and extent of trajectories (in a gradient from light blue to dark blue) for each stratum. (b) Projection of the rows of the initial sites $\times$ environments table (left column) and of the rows of the initial site $\times$ taxa table and (right column) into the compromise for each stratum. Labeled points indicate the mean position of taxa biomass or environmental variables for a given year. When the environment and taxa have the same trajectory (red dashed arrows), the environmental variables are considered to explain the variation in taxa biomass.

Fig 7(a). Pelagic trawl effort $\log (x+1)$ and 7(b). Bottom trawl effort $\log (x+1)$, transformed as in the STATICO analysis $(\log (x+1)$ hours fished per statistical rectangle). No pelagic trawl effort was recorded in white rectangles.

This article is protected by copyright. All rights reserved 
Fig 8(a). Spatio-temporal values of bottom temperature $\left({ }^{\circ} \mathrm{C}\right)$ and $8(\mathrm{~b})$. Slope of the regression of bottom temperature over time $\left({ }^{\circ} \mathrm{C} / \mathrm{y}\right)$. Only pixels with $p>0.1$ are plotted. See Appendix 2 for methodological details.

This article is protected by copyright. All rights reserved 


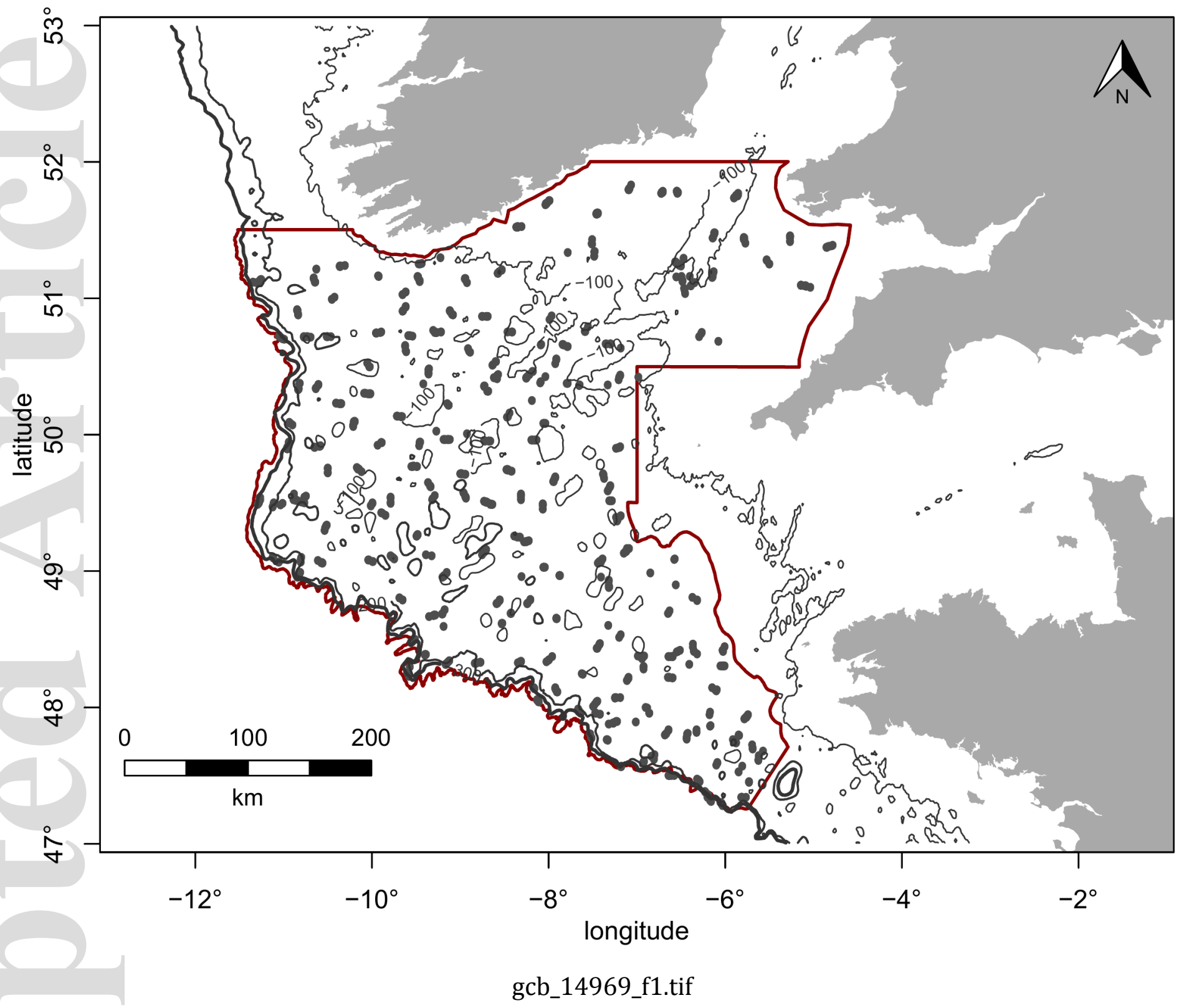

This article is protected by copyright. All rights reserved 


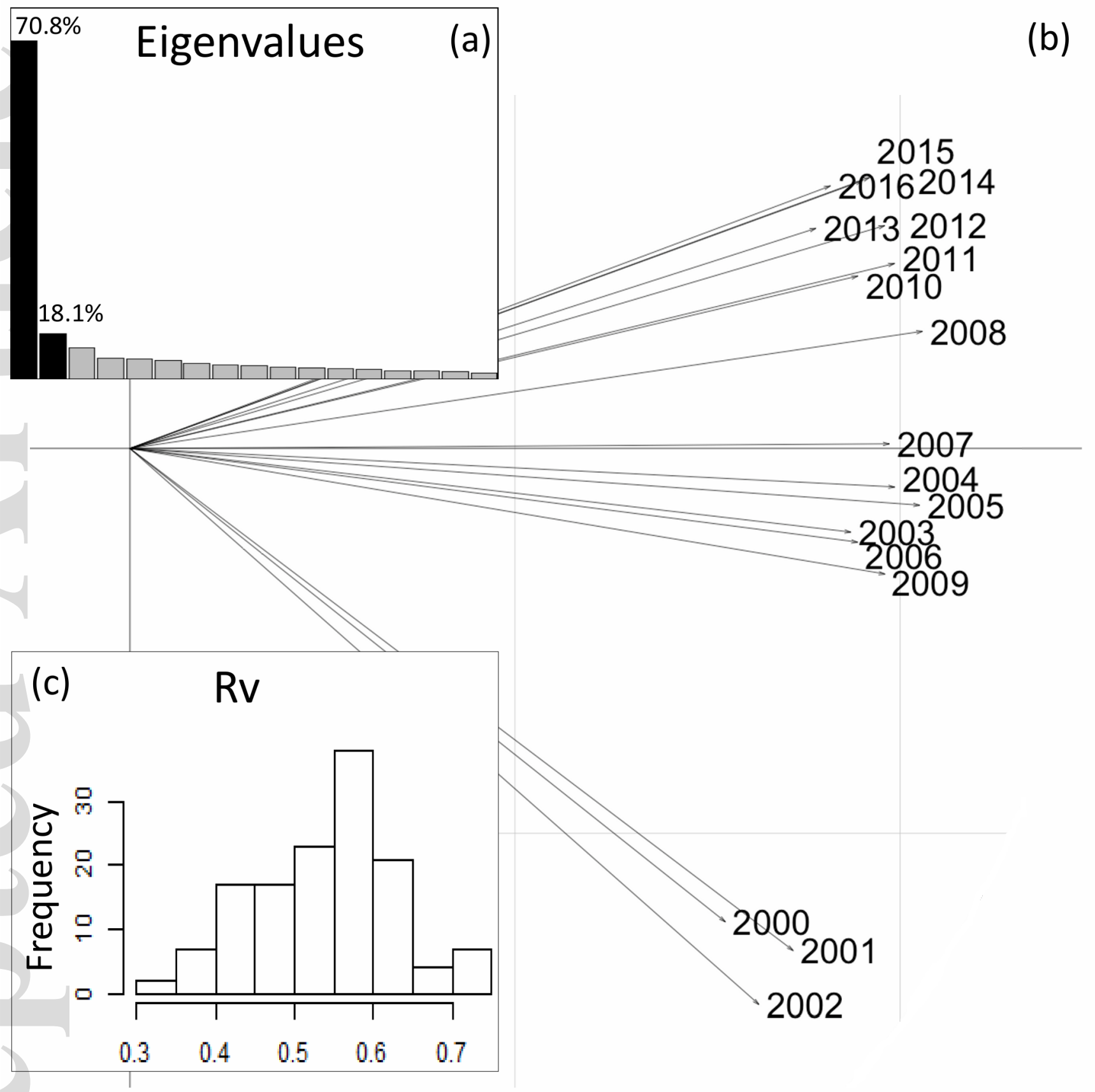

gcb_14969_f2.tif

This article is protected by copyright. All rights reserved 


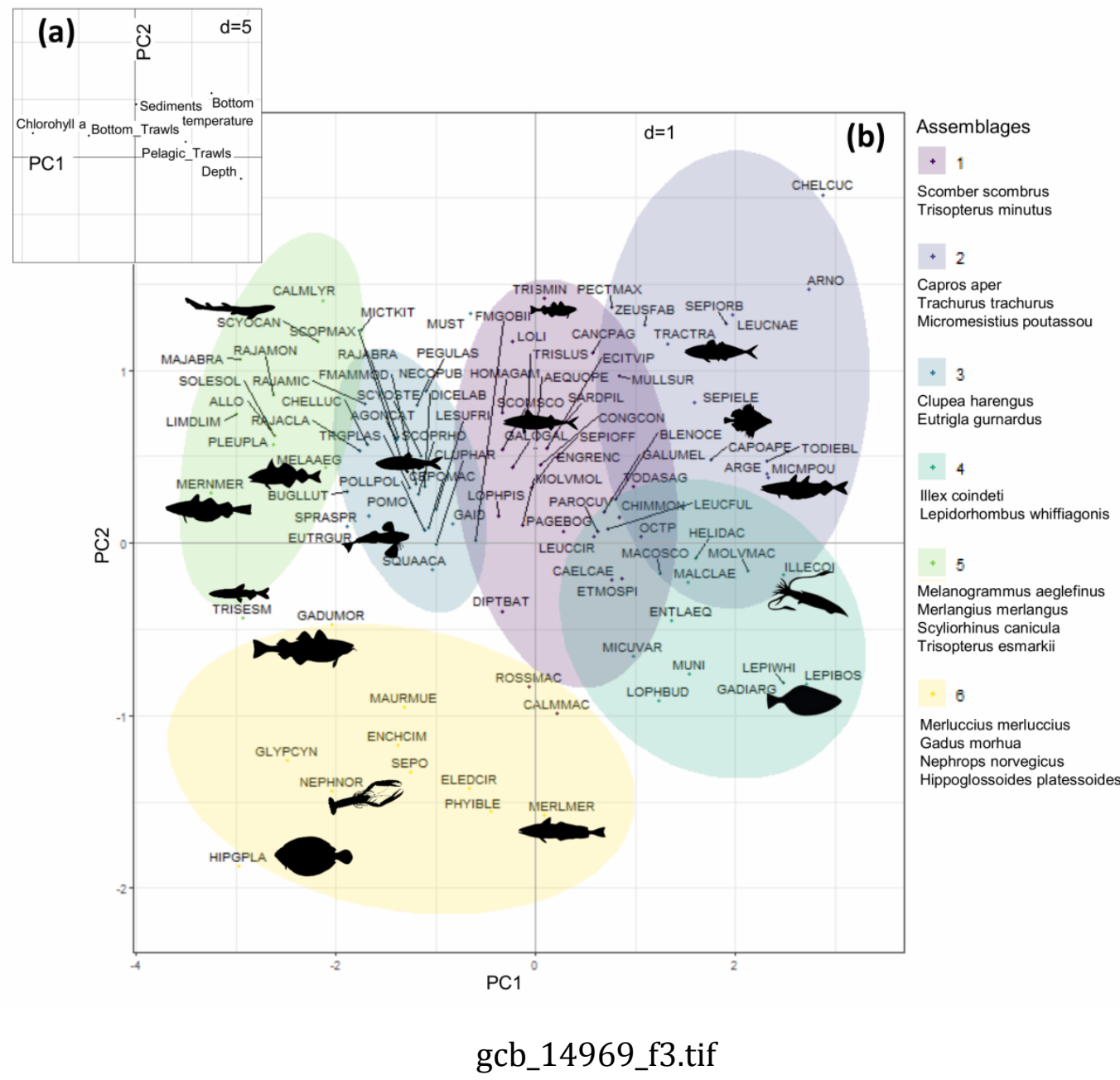

This article is protected by copyright. All rights reserved 


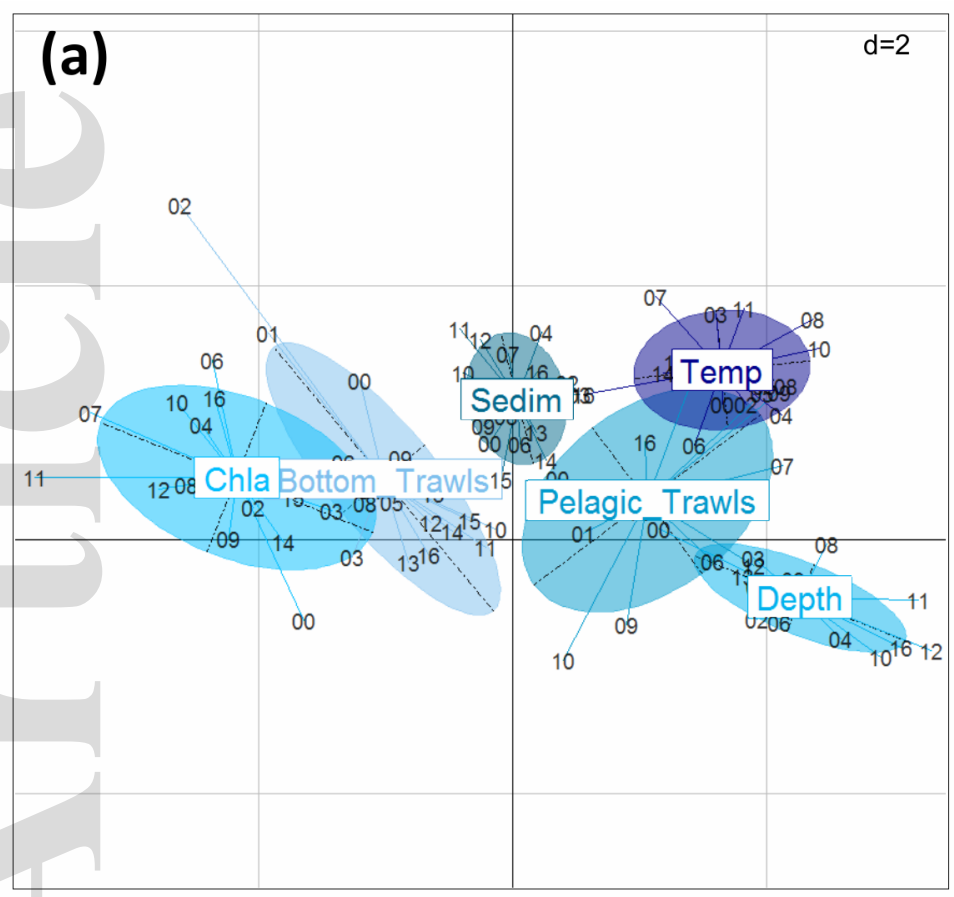

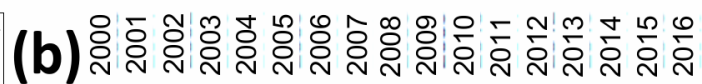
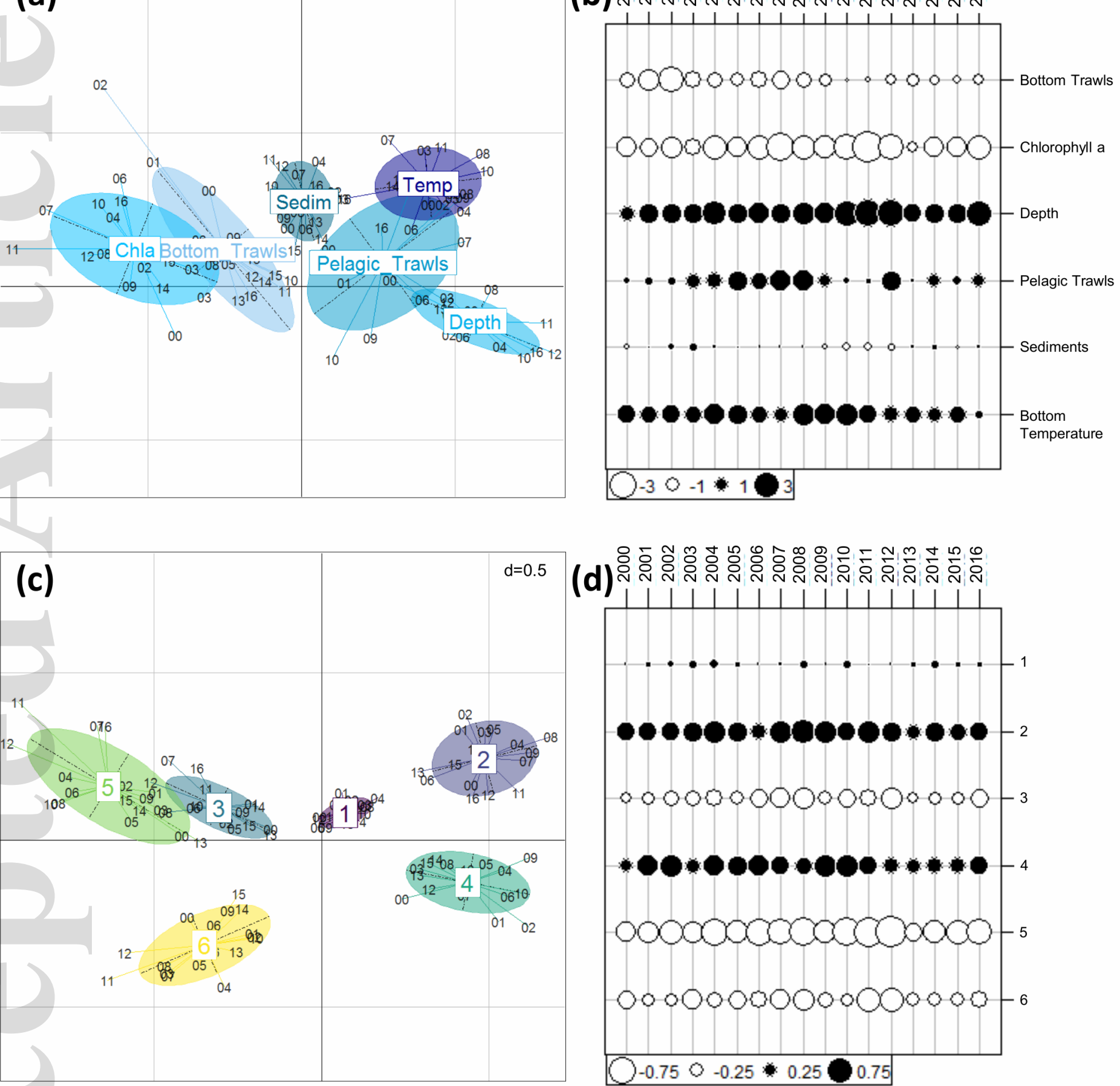

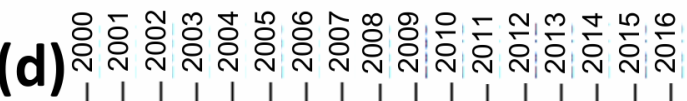

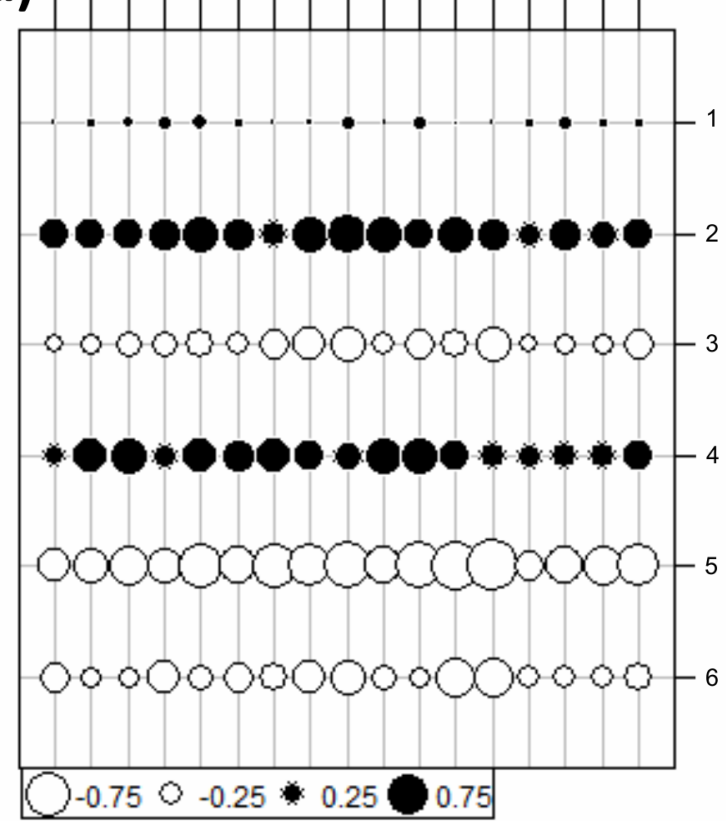

gcb_14969_f4.tif

This article is protected by copyright. All rights reserved 


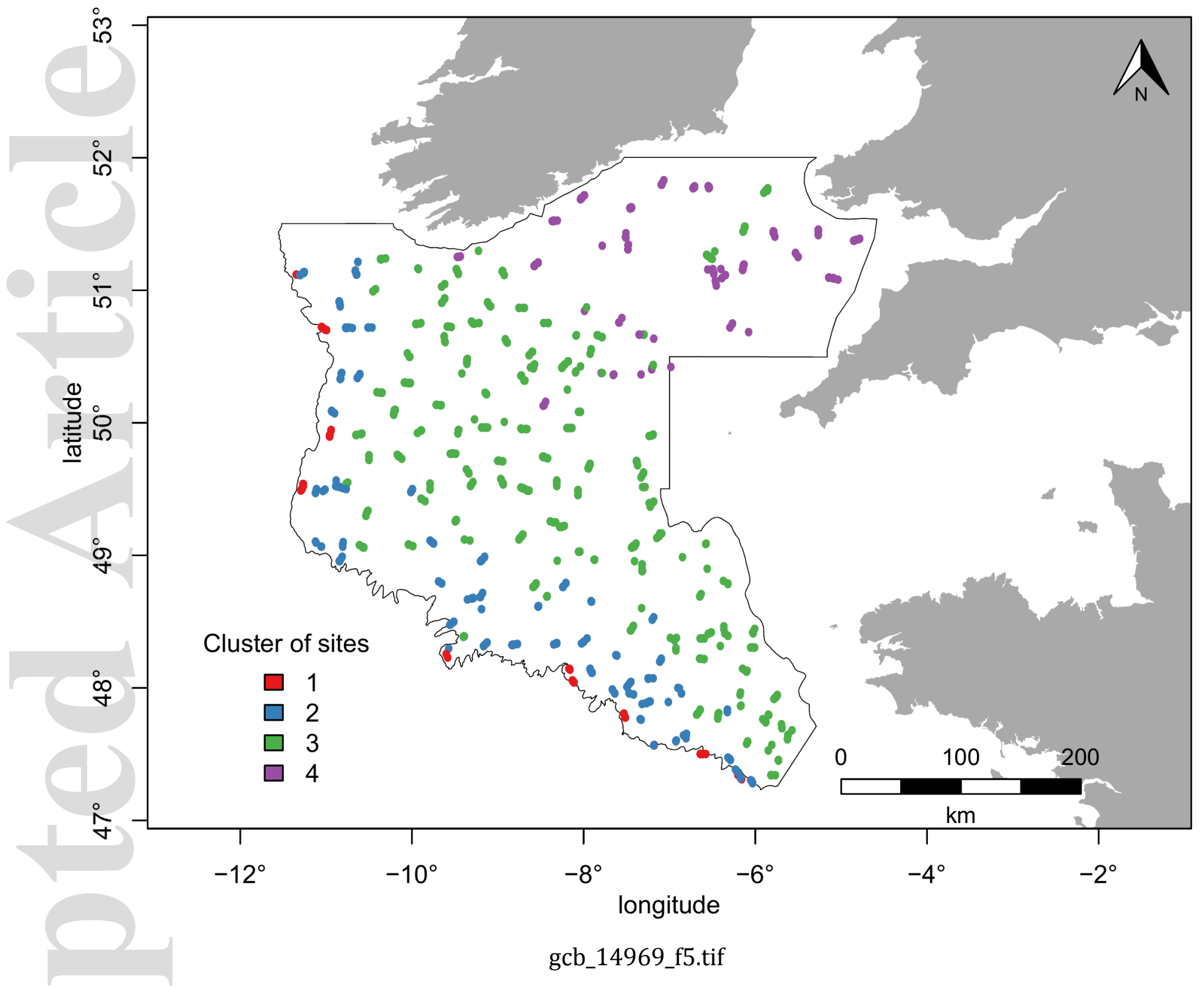

This article is protected by copyright. All rights reserved 
(a)

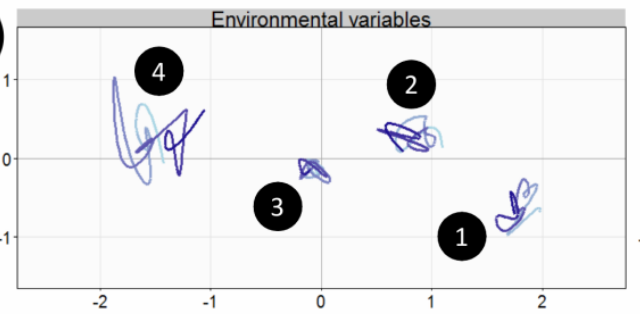

(b)

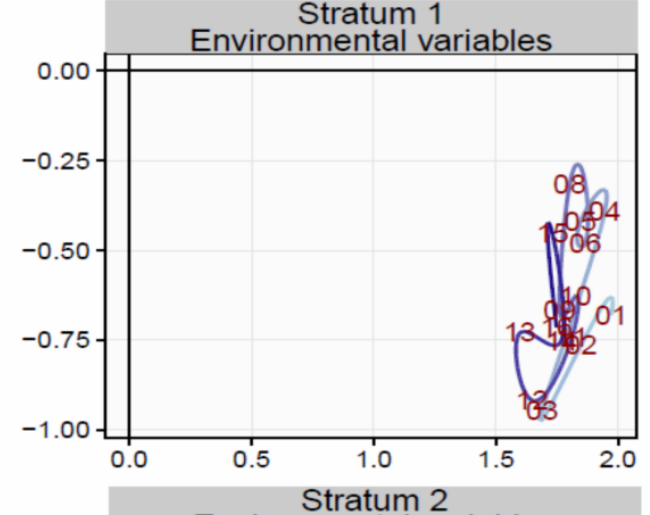

Environmental variables

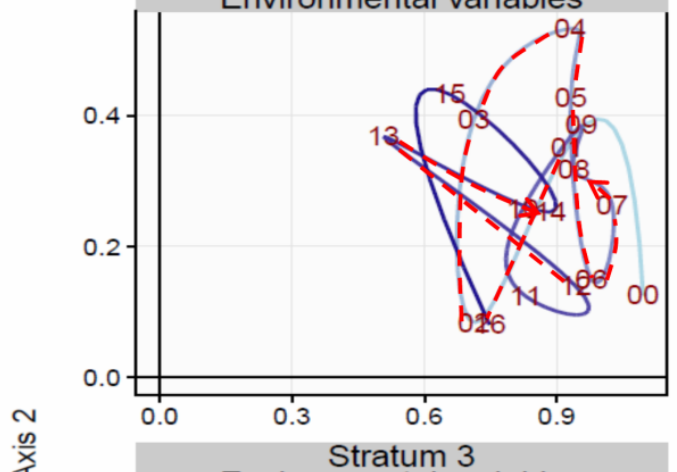

$\stackrel{\infty}{x}$
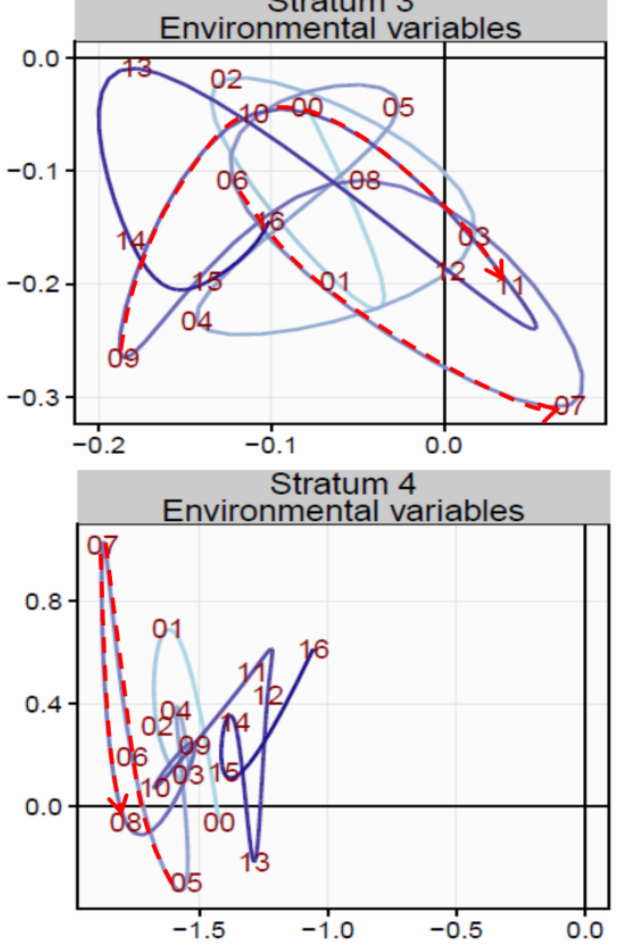

Axis 1

$\begin{array}{llllll}\text { Years } & & & & & \\ & 0 & 4 & 8 & 12 & 16\end{array}$
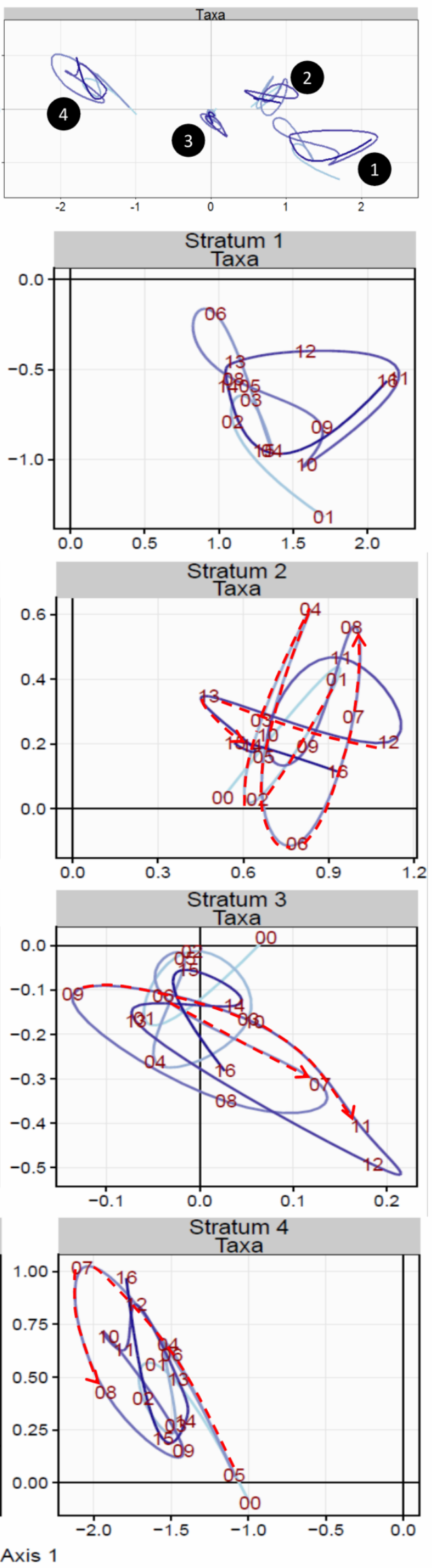

This article is protected by copyright. All rights reserved 
(a)

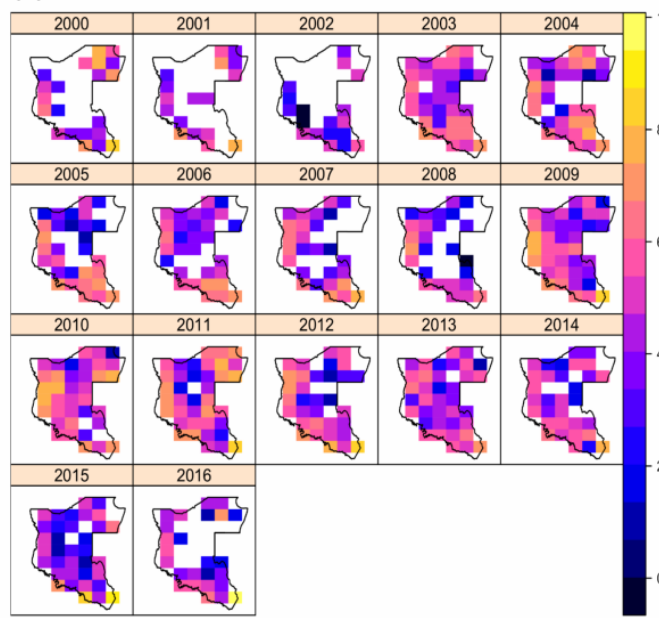

(b)

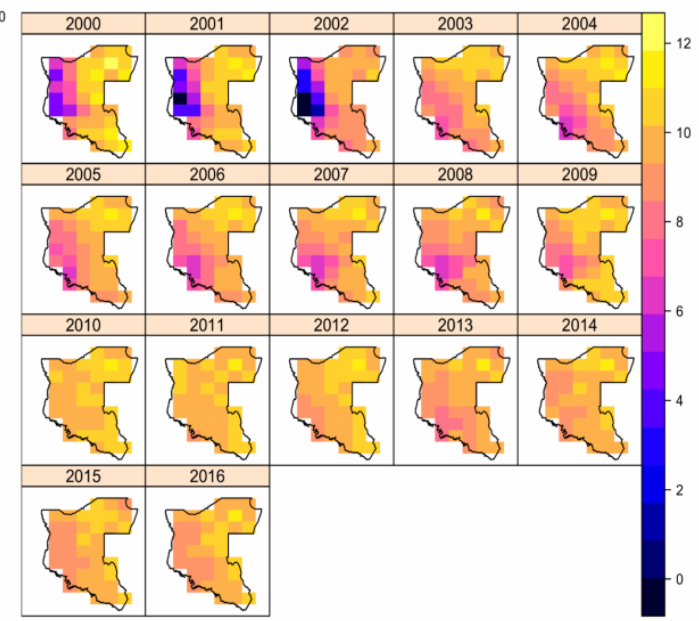

gcb_14969_f7.tif 


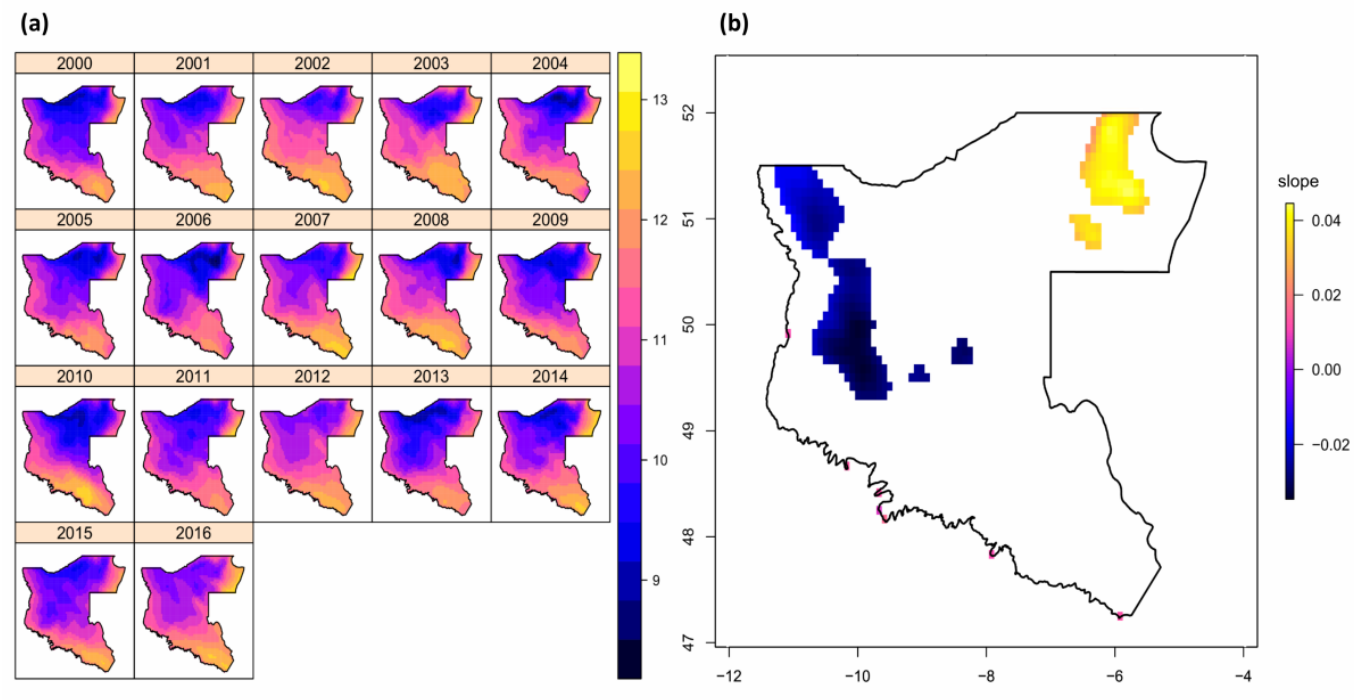

gcb_14969_f8.tif

This article is protected by copyright. All rights reserved 